\title{
PENGARUH KOMITMEN ORGANISASI, KEPRIBADIAN DASAR, KOMPETENSI DOSEN, BUDAYA MIKRO, DAN SOCIAL CAPITAL TERHADAP KINERJA DOSEN DI UNIVERSITAS NEGERI GORONTALO
}

\author{
Abdul Rahmat dan Jimmy Herman Sinaulan \\ Lecturer in the State University of Gorontalo dan Indonesia dan Program DIM \\ Unsoed-Indonesia \\ Email: abdulrahmat@ung.ac.id dan hermansina@gmail.com
}

\begin{abstract}
The results showed: faculty commitment to the organization, are synthesized as loyalty to and involvement in campus activities. Whereas the competence of lecturers are synthesized as capabilities in the process of influencing and mobilizing others. Basic personality can not be separated from the micro-culture. In addition to micro-culture, a lecturer confidence level factor to influence from within or outside, or so-called source-control, play an important role in the relationship between the three independent variables with the performance of a teacher. Source-control is strong, will make a commitment to the organization of a lecturer, able to determine and select the best activities for the advancement of the organization. Source-control social capital that is capable of providing one's spirit, unyielding, not easily swayed into negative thing to achieve desired goals.
\end{abstract}

Keywords: commitment, personality, social capital, and the performance of lecturers

\begin{abstract}
Abstrak: Hasil penelitian menunjukkan: komitmen dosen terhadap organisasi, disintesiskan sebagai kesetiaan terhadap kampus dan keterlibatan di dalam aktivitasnya. Sedangkan kompetensi dosen disintesiskan sebagai kemampuan yang dimiliki dalam proses mengarahkan dan menggerakkan orang lain. Kepribadian-dasar tidak lepas dari budaya-mikro. Selain budaya-mikro, faktor tingkat kepercayaan seorang dosen terhadap pengaruh dari dalam maupun luar, atau disebut sumber-kendali, berperan penting terhadap hubungan antara ketiga variabel independen tersebut dengan kinerja seorang dosen. Sumber-kendali yang kuat, akan membuat komitmen terhadap organisasi seorang dosen, mampu menentukan dan memilih aktivitasnya yang terbaik bagi kemajuan organisasi. Sumber-kendali yakni modal sosial mampu memberikan semangat seseorang, pantang menyerah, tidak mudah tergoyahkan ke hal negatif untuk mencapai tujuan yang diinginkan.
\end{abstract}

Kata kunci: komitmen, keperibadian, modal sosial, dan kinerja dosen

\section{PENDAHULUAN}

Fenomena di lapangan masih dijumpai kinerja dosen yang kurang optimal karena adanya komitmen yang rendah. Komitmen yang rendah dapat disebabkan oleh "dominasi petunjuk atasan", yaitu adanya pimpinan yang membuat peraturan/kebijakan tanpa koordinasi dengan pelaksana (dosen). Dosen sekedar sebagai pekerja yang kurang/tidak berperan dalam penentuan kebijakan kampus. Dalam tatanan manajerial, dosen berada 
dalam pola yang membuat dosen dalam posisi yang sangat tidak menunjang bagi perwujudan kinerja profesionalnya. Fenomena lain dijumpai, yaitu komitmen yang telah disepakati pada saat perencanaan, tidak dilaksanakan. Pelanggaran ini terjadi baik di tingkat pimpinan, maupun di tingkat dosen bersangkutan. Pengaruh yang ditimbulkan adalah ketidak-sesuaian antara perencanaan dan pelaksanaan, yang berakibat terhadap kinerja dosen menjadi turun. Adanya budaya yang statis-sentralistis di lingkungan pendidikan, disadari atau tidak, telah mempertebal konsep "given", seperti kebijakan yang sentralistis dan dukungan operasional yang kurang memadai.

Berdasarkan uraian di atas, penelitian ini menempatkan kinerja dosen sebagai fokus penelitian, yang dipengaruhi oleh komitmennya terhadap organisasi kampus, kepribadiandasar yang dimiliki dosen, kompetensi sebagai seorang dosen, serta dosen tidak memiliki modal sosial masih menunjukkan fenomena yang kurang mendukung proses pembelajaran di Indonesia.

Variabel-variabel (1) komitmen organisasi, (2) kepribadian-dasar, (3) kompetensi dosen (4) budaya-mikro (micro culture), dan (5) social capital, diperkirakan mempunyai hubungan dengan kinerja dosen. Bentuk dan besarnya hubungan variabel-variabel tersebut terhadap kinerja, perlu dibuktikan melalui penelitian, sehingga hasil dan rekomendasi yang diberikan berdasarkan analisis statistik, dapat dipertanggungjawabkan secara ilmiah.

Dalam penelitian ini dapat diuraikan rumusan masalah penelitian sebagai berikut: (1) Apakah terdapat hubungan positif antara komitmen organisasi dengan kinerja dosen, yang didukung moderator budaya-mikro dan social capital; (2) Apakah terdapat hubungan positif antara kepribadian-dasar dengan kinerja dosen, yang didukung moderator budayamikro dan social capital; (3) Apakah terdapat hubungan positif antara kompetensi dosen dengan kinerja dosen, yang didukung moderator budaya-mikro dan social capital; (4) Apakah terdapat hubungan positif antara komitmen organisasi, kepribadian-dasar dan kompetensi dosen secara bersama-sama dengan kinerja dosen, yang didukung moderator budaya-mikro dan social capital.

Tujuan Penelitian. Keberhasilan pendidikan ditentukan oleh berbagai faktor, di antaranya, kinerja dosen, sedangkan kinerja dosen juga ditentukan oleh berbagai faktor, di antaranya adalah (1) komitmen organisasi, (2) kepribadian-dasar, (3) kompetensi dosen, (4) budaya-mikro, dan (5) social capital dari dosen yang bersangkutan. Dengan demikian, tujuan penelitian ini adalah: (1) Mengetahui adanya hubungan antara komitmen organisasi dengan kinerja dosen, yang didukung moderator budaya-mikro dan social capital; (2) Mengetahui adanya hubungan antara kepribadian-dasar dengan kinerja dosen, yang didukung moderator budaya-mikro dan social capital; (3) Mengetahui adanya hubungan antara kompetensi dosen dengan kinerja dosen, yang didukung moderator budaya-mikro dan social capital; (4) Mengetahui adanya hubungan antara komitmen organisasi, kepribadian-dasar dan kompetensi dosen secara bersama-sama dengan kinerja dosen, yang didukung moderator budaya-mikro dan social capital.

\section{KAJIAN TEORI}

Konsep Kinerja Dosen. Kinerja merupakan fungsi dari interaksi antara kemampuan dan motivasi. Apabila kemampuan dan/atau motivasi seseorang tidak sesuai dengan yang dibutuhkan, maka akan berdampak negatif terhadap kinerjanya. "Employee performance is as a function (f) of the interaction of ability (A), and motivation (M), that is, 
performance $=f(A \times M)$. If either is inadequate, performance will be negatively affected" (Robbins, 2005:192).

Berdasarkan pendapat tersebut, maka kemampuan, termasuk kecerdasan dan keterampilan, perlu dipertimbangkan di samping motivasi pekerja, apabila diharapkan akurasi ramalan terhadap kinerja pekerja. "An individual's intelligence and skills (subsumed under the label ability) must be considered in addition to motivation if we are to be able to accurately explain and predict employee performance" (Robbins, 2005:192).

Pendapat di atas digambarkan oleh Robbins (2005:192) sebagai berikut:

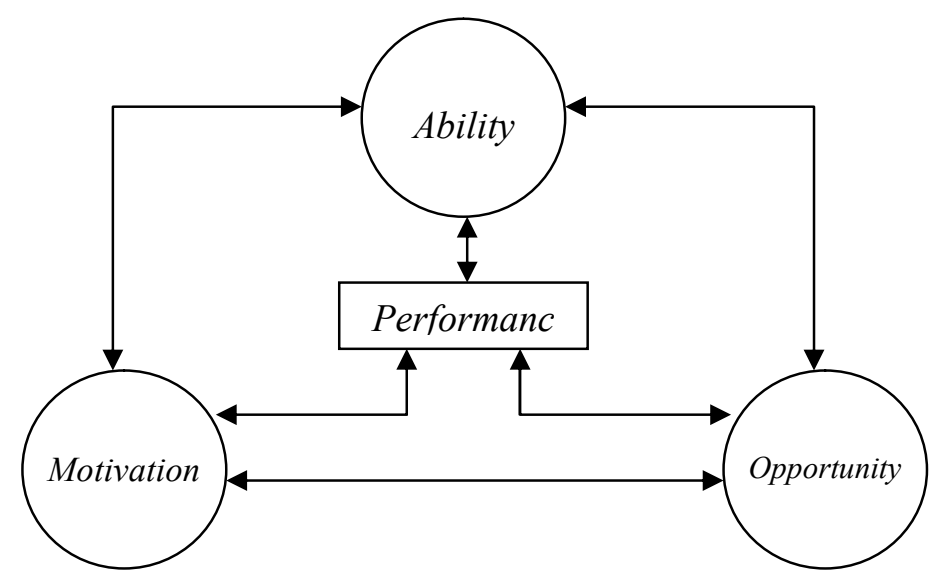

Gambar 1. Performance Dimensions

Sumber: Robins (2005: 192)

Dalam perencanaan kinerja dapat digunakan "Manajemen Berdasarkan Sasaran (Management By Objectives = MBO)". Management By Objectives merupakan sistem manajemen yang memasukkan partisipasi dalam pengambilan keputusan, penyusunan tujuan dan umpan-balik sasaran. "Management By Objectives is a management system that incorporates participation in decision making, goal setting, and objective feedback". (Kinicki \& Kreitner, 2003:146). Partisipasi di sini melibatkan pimpinan dan bawahan. "This process involves having the employee meet with his or her immediate supervisor prior to the time period for which perfomance is to be assessed". (Mello, 2002:307).

Secara lebih jelas, dapat dinyatakan bahwa Management By Objectives adalah sebuah sistem penyusunan tujuan kolaboratif dari pucuk pimpinan hingga bawah. Sistem ini melibatkan para pimpinan dan bawahan dalam penyusunan tujuan dan dalam menilai kemajuan. "Management By Objectives (MBO) is a system of collaborative goal setting that extends from the top of an organization to the bottom. MBO involves managers and subordinates in setting goals and evaluating progress". (Griffin \& Ebert, 2006:262).

Berdasarkan rumusan pengertian di atas, maka sasaran yang disusun pada tingkat bawah, cocok dengan sasaran-sasaran yang berada di tingkat atas. A suitable management objective should motivate the choice of metric and evaluation function, and thus the definition of a management objective is the first step in phrasing a control problem. We define what we mean by an objective in order to clarify this discussion and highlight the benefits of clearly defining management objectives. (Probert, 2015: 77)

The application of knowledge, skills and techniques to execute projects effectively and efficiently. It's a strategic competency for organizations, enabling them to tie project 
results to busi- ness objectives - and thus, better compete in their markets. (Meghann L. Drury-Grogan. 2014: 506-515).

Dari rumusan tersebut jelas bahwa bagi seorang dosen, job specification yang dibutuhkan sangat luas, tidak terbatas pada penguasaan materi pelajaran yang harus diberikan kepada peserta didik. Pertama. Penilaian kinerja adalah kegiatan mengidentifikasi pelaksanaan pekerjaan dengan menilai aspek-aspeknya, yang difokuskan pada pekerjaan yang berpengaruh pada kesuksesan organisasi. Kedua. Penilaian adalah kegiatan pengukuran (measurement) sebagai usaha menetapkan keputusan tentang sukses atau gagal dalam melaksanakan pekerjaan oleh seorang pekerja.

Altındă̆, Kösedağı (2015: 270-282) performance is a quantitative and qualitative expression, where the person, group or business doing the work can reach for intended destination related to this work.

Komitmen Organisasi. Schermerhorn (2005:385) merumuskan pengertian komitmen organisasi secara singkat, yaitu kesetiaan seorang individu kepada organisasi. "The loyalty of an individual to the organization".

Sedangkan Kinicki \& Kreitner, (2003:129) menyatakan bahwa "Organizational commitment reflects the extent to which an individual identifies with an organization and is committed to its goals".

Individu dengan komitmen yang tinggi akan kuat identifikasinya dengan organisasi dan mendapatkan kebanggaan sebagai anggota.. (Schermerhorn, 2005:385-386).

Adanya kebanggaan sebagai anggota organisasi, pekerja tidak hanya sekedar bekerja, tetapi disertai keberpihakan pada organisasi, serta berniat untuk memelihara keanggotaannya dalam organisasi itu.

Conducted a study investigating the relationship among organizational commitment, budgetary participation and budgetary slack and they revealed that organizational commitment shows determining effect on the relationship between budgetary participation and budgetary slack (Emine Y1lmaz, Gökhan, Özer \& Mehmet Günlük. 2014: 241-250).

Pemihakan seseorang kepada pekerjaannya, menunjukkan keterlibatan kerja yang tinggi. Komitmen yang tinggi pada organisasi menunjukkan adanya pemihakan. "High job involvement means identifying with one's specific job, while high organizational commitment means identifying with one's employing organization". (Robbins, 2005:79).

Pemihakan tersebut, diwujudkan dalam bentuk kesetiaan pekerja kepada organisasi, serta menunjukkan tingkat keterlibatannya dalam organisasi. Hal tersebut jelas dari pengertian komitmen organisasi. Komitmen organisasi merupakan kesetiaan karyawan kepada organisasi, serta tingkat keterlibatannya dalam organisasi. "Loyalty to and heavy involvement in one's organization". (Daft, 2003:484).

This notwithstanding in some cases organizational commitment may disturb social and personal functioning of employee as well as effective functioning of organization. The implications mostly depends on the component of commitment. Nonetheless, researchers frequently employ affective component of organizational commitment in order to explore positive consequences for employees or organizations (Giedrè Genevičiūtè-Janonienè \& Auksè Endriulaitienè. 2014: 558-564).

Berdasarkan jabaran tersebut, secara lebih singkat dapat dirumuskan sesuai dengan uraian sebelumnya, yaitu bahwa komitmen organisasi merupakan sebuah sikap yang mencerminkan kesetiaan para pekerja kepada organisasi mereka, sebagai proses berkelanjutan di mana para pekerja menyatakan perhatian mereka terhadap organisasi 
demi keberhasilan dan kesejahteraan secara berkelanjutan. Rendahnya komitmen terhadap organisasi, dapat diwujudkan pada tingginya stress para pekerja, biaya asuransi yang lebih tinggi dan lebih banyak tuntutan-tuntutan hukum. Konsekuensi dari ketidak-puasan kerja tersebut, langsung ataupun tidak langsung akan menambah biaya organisasi.

Konsep Kepribadian-Dasar. Kepribadian diartikan sebagai gabungan dari karakteristik pisik dan mental yang tidak berubah yang memberikan identitas individual. Karakteristik tersebut termasuk bagaimana seseorang melihat, berpikir, bertindak dan merasakan. Juga termasuk sifat, nilai, motif, cetak-biru turunan, sikap, reaktivitas emosional, kemampuan, citra-diri dan kecerdasan seseorang. In both instances, personality was more predictive for individuals who showed higher temporalconsistency. (Robie, Stephen D. Risavy. 2015:1621).

Makna dari fakta tersebut ialah bahwa pimpinan tidak dapat mengharapkan perubahan kepribadian pekerjanya dalam waktu dekat. Oleh karena itu, untuk maksud praktis, pimpinan harus memandang kepribadian pekerja sebagai sesuatu yang relatif tetap dalam waktu pendek.(George \& Jones, 2002:43).

The concept of human personality has been grappled with by scientists and philosophers alike, ho have tried to objectify and deconstruct it, as a way to formalize people's likes, dislikes, and ltimately who they are as individuals. Game researchers and psychologists have (Nagle, et al, 2015:10-24).

Berdasarkan uraian di atas, dapat disimpulkan bahwa faktor-faktor yang membentuk kepribadian adalah biological heritage dan life experiences. Life experiences tersebut diperoleh dari lingkungan.

Konsep Kompetensi. Dessler (2005:140) merumuskan pengertian kompetensi sebagai "Demonstrable characteristics of a person that enable performance of a job". Karakteristik tersebut mencakup pengetahuan dan keterampilan teknis dan antarpribadi individu. "Competence encompasses an individual's technical and interpersonal knowledge and skills. (Robbins, 2005: 356). Moreover, teachers' communication competencies are operationalized and depended upon as the primary resource for establishing effective family-school partnerships (Gartmeier, et al, 2015: 207-216).

Kompetensi dapat diklasifikasikan dalam 3 (tiga) kelompok, yaitu (1) personal characteristics, (2) Visionary, dan (3) organization specific.

Pertama. Personal characteristics. Karakteristik pribadi ini termasuk integritas pribadi, kematangan berpendapat, fleksibilitas, dan menghormati orang lain. Pekerja diharapkan mempunyai karakteristik ini, yang kemudian dikembangkan dan ditunjukkan dalam menghadapi situasi yang makin kompleks dan ambigus. (Milkovich \& Newman, 2005:164).

Kedua. Visionary. Ini merupakan kompetensi yang paling tinggi tingkatannya, yang dapat diekspresikan sebagai perspektif global yang dimilikinya, mempunyai gagasan dalam menggerakkan organisasi dengan arah yang baru, dan pandai menyampaikan pendapat tentang implikasi kecenderungan organisasi, baik dalam menghadapi persaingan, dalam peristiwa-peristiwa dunia, maupun dalam komunitas lokal. (Milkovich \& Newman, 2005:164).

Ketiga. Organization specific. Di antara dua kelompok di atas, terdapat kompetensi yang dilihat secara khusus ke organisasi tertentu dan fungsi tertentu, di mana kompetensi tersebut diterapkan. (Milkovich \& Newman, 2005: 164). 
Budaya-Mikro. Kebudayaan dimiliki oleh setiap masyarakat. Perbedaannya terletak pada kebudayaan masyarakat yang satu lebih sempurna daripada kebudayaan masyarakat lain, untuk memenuhi segala keperluan masyarakatnya. Dalam hubungan di atas, biasanya diberikan nama "peradaban" (civilization) kepada kebudayaan yang telah mencapai taraf perkembangan teknologi yang lebih tinggi.

Untuk kepentingan analisis, maka dari sudut struktur dan tingkatan dikenal adanya super-culture yang berlaku bagi seluruh masyarakat. Suatu super-culture biasanya dapat dijabarkan ke dalam cultures yang mungkin didasarkan pada kekhususan daerah, golongan etnik, profesi, dan seterusnya. Dalam suatu culture, mungkin berkembang lagi kebudayaan-kebudayaan khusus yang tidak bertentangan dengan kebudayaan "induk", lazimnya dinamakan subculture.

Budaya organisasi dibangun dari kepercayaan yang dipegang teguh secara mendalam tentang bagaimana organisasi seharusnya dijalankan atau beroperasi. Budaya merupakan sistem nilai organisasi dan akan mempengaruhi cara pekerjaan dilakukan dan cara para pelaku berprilaku.Orang bisa saja sangat mampu dan efisien tanpa tergantung orang lain,tetapi perilakunya tidak sesuai budaya organisasi, maka tidak akan berhasil dalam organisasi. Sagala (2013:245) Menyebutkan bahwa budaya organisasi merupakan seperangkat nilai yang mengontrol interaksi antar anggota dalam suatu organisasi dan juga dengan berbagai kalangan di luar organisasi. Organizational culture is one of the importance is aform of beliefs and values. (Syafii', et al, 2015: 1142-1147).

Soehardi (2013:256) mengemukakan bahwa budaya organisasi sebagai pola asumsiasumsi dasar oleh suatu kelompok tertentu telah ditemukan, dibuka, atau dikembangkan melalui pelajaran untuk memecahkan masalah-masalah adaptasi eksternal dan integrasi internal, dan yang telah berjalan cukup lama untuk dipandang sahih, dan oleh sebab itu diajarkan kepada anggota-anggota baru sebagai cara yang benar untuk memandang, berpikir, dan merasa dalam kaitannya dengan masalah-masalah tersebut.

Greenbberg (2015:122) menekankan bahwa budaya orgnaisasi sebagai kerangka berfikir kognitif yang berisi sikap, nilai, norma perilaku, dan ekspektasi yang dimiliki oleh anggota organisasi, sedangkan Creemers menyatakan bahwa budaya orgnaisasi adalah keseluruhan norma, nilai, keyakinan, dan asumsi yang dimiliki oleh anggota dalam organisasi.

Budaya organisasi menurut Robbins (2008:256) mengacu pada sebuah sistem makna bersama yang dianut oleh para anggota yang membedakan organisasi tersebut dengan organisasi lainnnya. Sistem makna bersama ini, ketika dicermati lebih seksama, adalah sekumpulan karakteristik kunci yang dijunjung tinggi oleh organisasi. Penelitian menunjukkan bahwa ada tujuh karakteristik utama yang secara keseluruhan merupakan hakikat kultur sebuah organisasi, yaitu (1) Inovasi dan keberanian mengambil resiko. Sejauh mana karyawan didorong untuk bersikap inovatif dan berani mengambil resiko. (2) perhatian pada hal-hal rinci. Sejauh mana karyawan diharapkan menjalankan presisi, analisis, dan perhatian pada hal-hal detil. (3) orientasi hasil. Sejauhmana manajemen berfokus lebih pada hasil ketimbang pada teknik dan proses yang digunakan untuk mencapai hasil tersebut. (4) Orientasi orang. Sejauhmana keputusan-keputusan manajemen mempertimbangkan efek dari hasil tersebut atas orang yang ada dalam organisasi. (5) Orientasi tim. Sejauh mana kegiatan-kegitan kerja diorganisasi pada tim ketimbang pada individu-individu. (6) Keagresifan. Sejauh mana orang bersikap agresif dan kompetitif ketimbang santai. (7) Stabilitas. Sejauh mana kegiatan-kegiatan organisasi menekankan dipertahankannya status quo dalam perbandingannya dengan pertumbuhan. 
Menurut Dwiana (2014 41-51) dalam pembahasan budaya, ruang publik bekerja secara universal dan dapat diterima sebagai nilai dasar dalam konteks di luar masyarakat melalui independensi dari pengaruh politik dan ekonomi.

Searah dengan pengertian-pengertian di atas, kebudayaan bisa dikelompokkan sebagai berikut: (1) Kebudayaan yang berlaku bagi setiap orang sebagai warga negara di antara warga negara lainnya di dunia dalam era globalisasi; (2) Kebudayaan suatu bangsa yang berlaku untuk bangsa di mana manusia itu hidup; (3) Kebudayaan khusus yang berlaku untuk masing-masing orang atau kelompok kecil.

Social Capital. Modal sosial dapat didefinisikan sebagai kemampuan masyarakat untuk bekerja bersama, demi mencapai tujuan-tujuan bersama, di dalam berbagai kelompok. Sejumlah kejanggalan dan kegagalan tersebut muncul di permukaan karena para ekonom penganut mazab neo-klasik menganggap bawa faktor-faktor kultural dari perilaku manusia sebagai makluk rasional dan memiliki kepentingan diri menjadi sesuatu yang given/dikesampingkan. Singkatnya kehidupan ekonomi tidak bisa dipisahkan dari kebudayaan, dimana kebudayaan membentuk seluruh aspek manusia, termasuk perilaku ekonomi dengan sejumlah cara yang kritis.

Menurut Pattussi' et al, (2015: 411) Social capital has been defined as the resources derived from membership in social networks. At the individual level, these resources include access to information, the exchange of tangible resources, as well as social reinforcement. At the group level, social capital consists of group solidarity and cohesion, which in turn enables the collective to undertake coordinated action and to enforce social norms.

Motivasi ekonomi sebagai sesuatu yang sangat kompleks tertancap dalam kebiasaankebiasaan serta aturan-aturan yang lebih luas. Oleh karenannya aktivitas ekonomi merepresentasikan bagian yang krusial dari kehidupan sosial dan diikat bersama oleh varietas yang luas dari norma-norma, aturan-aturan, kewajiban-kewajiban moral, dan kebiasaan-kebiasaan lain yang bersama-sama membentuk masyarakat dan organisasi. Jousairi (2014:88)

Modal sosial sebagai serangkaian nilai-nilai atau norma-norma informal yang dimiliki bersama diantara para anggota suatu kelompok yang memungkinkan terjalinnya kerjasama di antara mereka. Modal sosial sebagai suatu rangkaian proses hubungan antar manusia yang ditopang oleh jaringan, norma-norma, dan kepercayaan sosial yang memungkinkan efisien dan efektifnya koordinasi dan kerjasama untuk keuntungan dan kebajikan bersama.

Modal sosial sebagai hubungan-hubungan yang tercipta dan norma-norma yang membentuk kualitas dan kuantitas hubungan sosial dalam masyarakat dalam spektrum yang luas, yaitu sebagai perekat sosial (social glue) yang menjaga kesatuan anggota kelompok secara bersama-sama. Modal sosial sebagai serangkaian nilai-nilai atau normanorma yang diwujudkan dalam perilaku yang dapat mendorong kemampuan dan kapabilitas untuk bekerjasama dan berkoordinasi untuk menghasilkan kontribusi besar terhadap keberlanjutan produktivitas.

Modal sosial adalah sebagai setiap hubungan yang terjadi dan diikat oleh suatu kepercayaan (trust), kesaling pengertian (mutual understanding), dan nilai-nilai bersama (shared value) yang mengikat anggota kelompok untuk membuat kemungkinan aksi bersama dapat dilakukan secara efisien dan efektif. Modal sosial sebagai segala sesuatu hal yang berkaitan dengan kerja sama dalam masyarakat atau bangsa untuk mencapai 
kapasitas hidup yang lebih baik, ditopang oleh nilai-nilai dan norma yang menjadi unsurunsur utamanya sepetri trust (rasa saling mempercayai), keimbal-balikan, aturan-aturan kolektif dalam suatu masyarakat atau bangsa dan sejenisnya. Modal sosial merupakan sumberdaya sosial yang dapat dipandang sebagai investasi untuk mendapatkan sumberdaya baru dalam masyarakat. Oleh karena itu modal sosial diyakini sebagai salah satu komponen utama dalam menggerakkan kebersamaan, mobilitas ide, kesalingpercayaan dan kesaling menguntungkan untuk mencapai kemajuan bersama.

Berdasarkan pengertian di atas modal sosial adalah suatu konsep dengan berbagai definisi yang saling terkait, yang didasarkan pada nilai jaringan sosial. Modal sosial terkadang merupakan sesuatu yang sangat tidak riil dan tampaknya sangat susah untuk sekedar dibayangkan. Modal sosial pendidikan timbul dari adanya interaksi antara orangorang dalam komunitas pendidikan. Sedangkan problematika yang terjadi antara lain pranata sosial, kepercayaan, dan jaringan sosial.

\section{METODE}

Penelitian ini merupakan suatu survei dengan metode penelitian penjelasan (explanatory survey method), yaitu suatu metode yang digunakan untuk menjelaskan dan menerangkan gejala yang telah terjadi (expo de facto), yang dialami oleh responden. Permasalahan penelitian berupa hubungan sebab akibat (Causal relationship) antara variabel - variabel penelitian, yaitu hubungan antara variabel dependen dengan variabelvariabel independen, dan variabel-variabel moderator (moderating variables) yang membentuk suatu susunan tertentu.

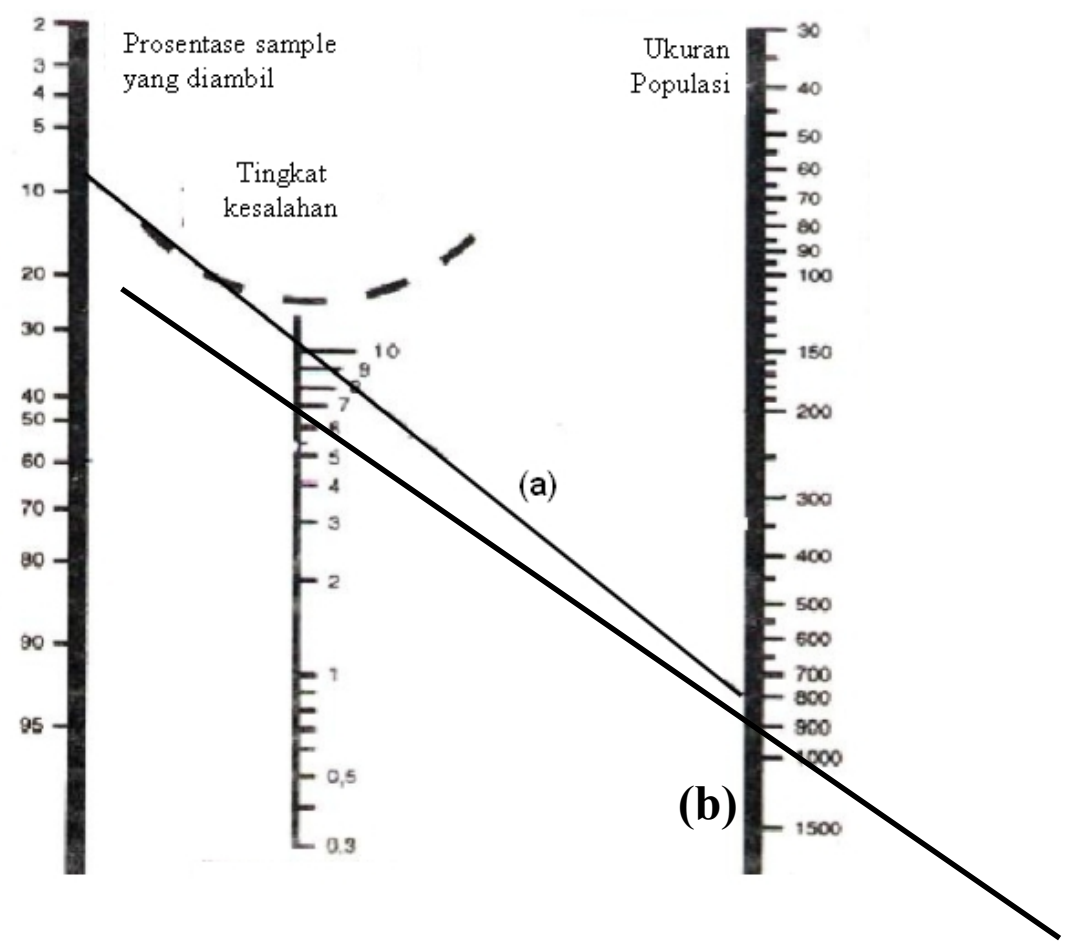

Gambar 2. Nomogram Harry King Untuk Menentukan Ukuran Sampel Dari Suatu Populasi Sampai 2.000. 
Pada Gambar 2 di muka, sesuai dengan susunan yang ada antar-variabel, analisis menggunakan Multivariat Linear Regression (MLR). Alat bantu perhitungan digunakan komputer dengan sofware yang sesuai.

Penelitian ini dilaksanakan di Provinsi Gorontalo. Pelaksanaan penelitian sejak Maret-Juni 2015. Penelitian ini menggunakan teknik pengambilan sampel berdasarkan Nomogram Harry King yang digambarkan Sugiyono (2013:66) seperti terlihat pada Gambar 2.

Teknik pengambilan sampel dengan menggunakan "Purposive Cluster Random Sampling" yaitu pengambilan sampel dilakukan dengan mengelompokkan wilayah, kemudian masing-masing kelompok diambil beberapa sampel dari populasi kelompok bersangkutan.

\section{HASIL DAN PEMBAHASAN}

Hubungan antara Komitmen Organisasi Kampus $\left(X_{1}\right)$ dengan Kinerja Dosen $(Y)$. Pengujian dengan menggunakan teknik analisis regresi dan korelasi sederhana. Analisis regresi sederhana $Y$ atas $X_{1}$ menghasilkan persamaan garis linier $Y=67,84+0,517 X_{1}$. Pada persamaan regresi tersebut, nilai konstanta adalah 67,84. Nilai koefisien variabel $\mathrm{X}_{1}$ adalah 0,517 , artinya bahwa setiap unit kenaikan 1 unit komitmen organisasi akan menaikkan 0,517 unit kinerja dosen ditambah dengan nilai konstanta 67,84.

Hasil dari proses perhitungan linearitas dan uji keberartian regresi, didapatkan beberapa harga yang dapat digunakan sebagai dasar membuat kesimpulan. Hasil analisis ditunjukkan pada tabel Anava sebagai berikut.

Tabel 1. Tabel Anava untuk Uji Signifikansi dan Linearitas Regresi

\begin{tabular}{cccrrr} 
& $\hat{Y}$ & linear & \multicolumn{1}{c}{$=67,84+0,517 \mathrm{X}_{1}$} & & \\
\hline Sumber Varian & $\mathrm{Db}$ & \multicolumn{1}{c}{$\mathrm{JK}$} & $\mathrm{RJK}$ & $\mathrm{F}_{\text {hitung }}$ & $\begin{array}{c}\mathrm{F}_{\text {tabel }} \\
\square=0,05\end{array}$ \\
\hline Total & 78 & 1571154.00 & & & \\
Regresi (a) & 1 & 1554588.80 & 1554588.80 & & \\
Regresi (b/a) & 1 & 5587,41 & 5587,41 & 39,70 & 3,96 \\
Sisa & 78 & 10977,79 & 140,74 & & \\
Tuna Cocok & 35 & 5132,91 & 146,65 & 1,079 & 1,68 \\
Galat & 43 & 5844,88 & 135,93 & & \\
\hline
\end{tabular}

Keterangan:

$* *=$ Regresi sangat signifikan $\left(\mathrm{F}_{\mathrm{h}}=39,70>\mathrm{F}_{\mathrm{t}(0,05)}=3,96\right) ;{ }^{\mathrm{ns}}=$ Regresi berbentuk linear $\left(\mathrm{F}_{\mathrm{h}} 1,079<\mathrm{F}_{\mathrm{t}(0,05)}=1,68\right) ; \mathrm{db}=$ derajat bebas; JK = Jumlah Kuadrat; RJK = Rerata Jumlah Kuadrat

Berdasarkan Tabel 1, hasil perhitungan uji signifikansi regresi menunjukkan harga regresi $F_{\text {hitung }}$ diperoleh nilai sebesar 39,70. Sedangkan harga $F_{\text {tabel }}$ dengan db pembilang = $\mathrm{db}$ regresi yaitu 1 dan penyebut $=\mathrm{db}$ sisa yaitu 78 pada taraf signifikansi 0,05 adalah sebesar 3,96 didapatkan bahwa nilai $\mathrm{F}_{\text {hitung }}>\mathrm{F}_{\text {tabel. }}$ 
Dari hasil tersebut di atas, dapat disimpulkan bahwa regresi "sangat signifikan" dengan persamaan $\mathrm{Y}=67,84+0,517 \mathrm{X}_{1}$, atau dengan kata lain terdapat hubungan yang signifikan dan berbentuk persamaan regresi linear antara komitmen organisasi dengan kinerja dosen. Persamaan ini dapat diartikan bahwa peningkatan satu unit nilai pada komitmen organisasi menyebabkan peningkatan sebesar 0,517 unit ditambah nilai konstanta 67,84 unit nilai pada kinerja dosen.

Hasil dari perhitungan uji linearitas didapatkan $F_{\text {tuna cocok }}$ sebesar 0,75 sedangkan $\mathrm{F}_{\text {tabel }}=1,69$ pada taraf signifikan 0,05 (dengan pembilang $=\mathrm{db}$ tuna cocok $=35$, dan penyebut $=\mathrm{db}$ galat $=43$ ). Dengan demikian bahwa nilai $\mathrm{F}_{\text {tuna cocok }}<$ dari $\mathrm{F}_{\text {tabel. }}$. Dari hasil tersebut dapat simpulkan bahwa bentuk regresi $\mathrm{Y}$ atas $\mathrm{X}_{1}$ adalah linear.

Bentuk hubungan antara komitmen organisasi kampus dengan kinerja dosen melalui persamaan $\mathrm{Y}=67,84+0,517 \mathrm{X}_{1}$ dapat digambarkan dalam bentuk model hubungan pada gambar sebagai berikut:

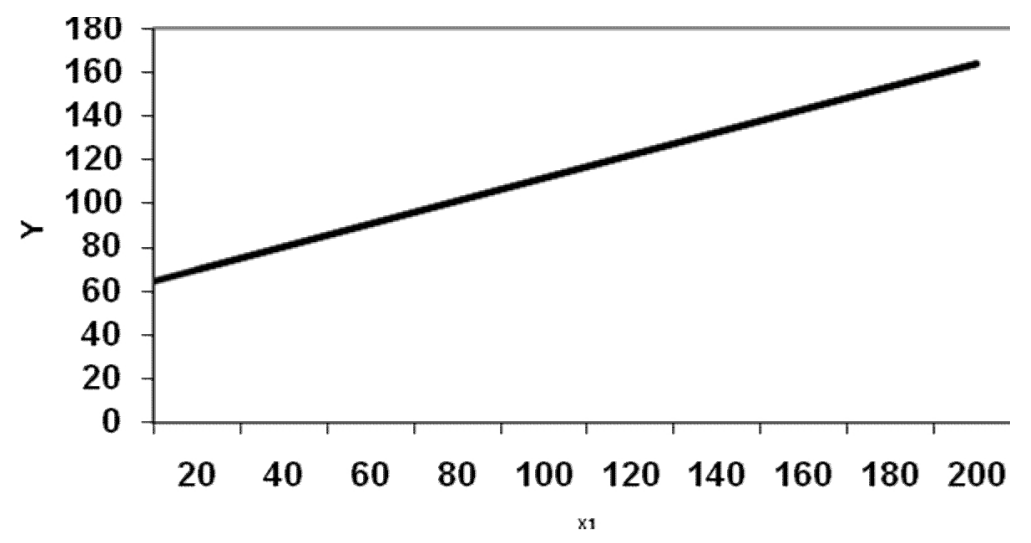

Gambar 3. Model Hubungan Antara Komitmen Organisasi Kampus dengan Kinerja Dosen.

Nilai koefisien korelasi sederhana $\left(\mathrm{r}_{\cdot} \cdot \mathrm{yl}\right)$ antara komitmen organisasi kampus $\left(\mathrm{X}_{1}\right)$ dengan kinerja dosen (Y) sebesar 0,5808. Dengan hasil nilai tersebut, berarti antara komitmen organisasi kampus dengan kinerja dosen saling keterkaitan sebesar 58,08 \%. Hasil hitung pengujian keberartian korelasi dengan menggunakan uji-t menghasilkan $\mathrm{t}_{\text {hitung }}=15,48$. Nilai $\mathrm{t}_{\text {tabel }}$ dengan daftar distribusi $\mathrm{t}$ untuk $\mathrm{db}=78$ dan taraf signifikansi

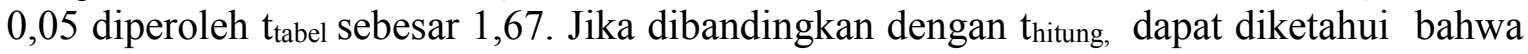
nilai $t_{\text {hitung }}>\mathrm{t}_{\text {tabel, }}$, sehingga dapat disimpulkan bahwa antara komitmen organisasi dengan kinerja dosen menunjukkan korelasi "signifikansi berarti".

Nilai koefisien determinasi diperoleh dengan mengkuadratkan nilai koefisien korelasi antara $\mathrm{X}_{1}$ dengan $\mathrm{Y}$ yaitu sebesar $(0,5808)^{2}=0,3373$. Nilai tersebut mengartikan bahwa sekitar 33,73 \% variasi yang terjadi pada kinerja dosen dapat dijelaskan oleh variasi komitmen organisasi melalui persamaan regresi sederhana, yaitu $\mathrm{Y}=67,84+0,517 \mathrm{X}_{1}$.

Hubungan antara Kepribadian-dasar $\left(\mathrm{X}_{2}\right)$ dengan Kinerja Dosen (Y). Pengujian dengan menggunakan teknik analisis regresi dan korelasi sederhana. Analisis regresi sederhana $\mathrm{Y}$ atas $\mathrm{X}_{2}$ menghasilkan persamaan garis linier $=46,03+0,68 \mathrm{X}_{2}$. Pada persamaan regresi tersebut nilai konstanta adalah 46,03 . Nilai koefisien variabel $X_{2}$ adalah 
0,68 artinya bahwa setiap unit kenaikan 1 unit kepribadian-dasar akan menaikkan 0,68 unit kinerja dosen ditambah dengan nilai konstanta 46,03.

Hasil dari proses perhitungan linearitas dan uji keberartian regresi, didapatkan beberapa harga yang dapat digunakan sebagai dasar membuat kesimpulan. Hasil analisis ditunjukkan pada tabel Anava sebagai berikut.

Tabel 2. Tabel Anava untuk Uji Signifikansi dan Linearitas Regresi

\begin{tabular}{ccrrrr} 
& $\hat{Y}$ & \multicolumn{2}{c}{ linear $=46,03+0,680 \mathrm{X}_{2}$} & & \\
\hline Sumber Varian & $\mathrm{Db}$ & $\mathrm{JK}$ & $\mathrm{RJK}$ & $\mathrm{F}_{\text {hitung }}$ & $\begin{array}{c}\mathrm{F}_{\text {tabel }} \\
\square=0,05\end{array}$ \\
\hline Total & 78 & 1571154.00 & & & \\
Regresi (a) & 1 & 1554588.80 & 1554588.80 & & \\
Regresi (b/a) & 1 & 8680,46 & 8680,46 & 85,87 & 3,96 \\
Sisa & 78 & 7884,74 & 101,09 & & \\
Tuna Cocok & 39 & 2525,32 & 64,75 & 0,471 & 1,69 \\
Galat & 39 & 5359,42 & 137,42 & & \\
\hline
\end{tabular}

Keterangan: $* *=$ Regresi sangat signifikan $\left(\mathrm{F}_{\mathrm{h}}=85,87>\mathrm{F}_{\mathrm{t}(0,05)}=3,96\right) ;{ }^{\mathrm{ns}}=$ Regresi berbentuk linear $\left(\mathrm{F}_{\mathrm{h}} 0,, 471<\mathrm{F}_{\mathrm{t}(0,05)}=1,69\right)$; $\mathrm{db}=$ derajat bebas; JK = Jumlah Kuadrat; $\mathrm{RJK}=$ Rerata Jumlah Kuadrat

Berdasarkan Tabel 2, hasil perhitungan uji signifikansi regresi menunjukkan harga regresi $F_{\text {hitung }}$ diperoleh nilai sebesar 85,87 . Sedangkan harga $F_{\text {tabel }}$ dengan db pembilang $=$ $\mathrm{db}$ regresi yaitu 1 dan penyebut $=\mathrm{db}$ sisa yaitu 78 pada taraf signifikansi 0,05 adalah sebesar 3,96 didapatkan bahwa nilai $\mathrm{F}_{\text {hitung }}>\mathrm{F}$ tabel.

Dari hasil tersebut di atas, dapat disimpulkan bahwa regresi "sangat signifikan" dengan persamaan $\mathrm{Y}=46,03+0,680 \mathrm{X}_{2}$, atau dengan kata lain terdapat hubungan yang signifikan dan berbentuk persamaan regresi linear antara kepribadian-dasar dosen dengan kinerja dosen. Persamaan ini dapat diartikan bahwa peningkatan satu unit nilai pada kepribadian-dasar menyebabkan peningkatan sebesar 0,680 unit ditambah nilai konstanta 46,03 unit nilai pada kinerja dosen.

Hasil dari perhitungan uji linearitas didapatkan $F_{\text {tuna cocok }}$ sebesar 0,471 sedangkan $\mathrm{F}_{\text {tabel }}=1,69$ pada taraf signifikan 0,05 (dengan pembilang $=\mathrm{db}$ tuna cocok $=39$, dan penyebut $=\mathrm{db}$ galat $=39)$. Dengan demikian bahwa nilai $\mathrm{F}_{\text {tuna cocok }}<$ dari $\mathrm{F}_{\text {tabel. }}$. Dari hasil tersebut dapat simpulkan bahwa bentuk regresi $\mathrm{Y}$ atas $\mathrm{X}_{1}$ adalah linear.

Bentuk hubungan antara kepribadian-dasar dengan kinerja dosen melalui persamaan $\mathrm{Y}=46,03+0,680 \mathrm{X}_{2}$ dapat digambarkan dalam bentuk model hubungan seperti terlihat pada Gambar 4.

Nilai koefisien korelasi sederhana ( $\mathrm{r}_{\mathrm{y}} \mathrm{y}$ ) antara kepribadian-dasar $\left(\mathrm{X}_{2}\right)$ dengan kinerja dosen ( Y ) sebesar 0,7239. Dengan hasil nilai tersebut berarti antara kepribadiandasar dengan kinerja dosen saling ada keterkaitan sebesar 72,39\%. Hasil hitung pengujian keberartian korelasi dengan menggunakan uji-t menghasilkan $t_{\text {hitung }}=26,86$. Nilai $t_{\text {tabel }}$ dengan daftar distribusi $t$ untuk $\mathrm{db}=78$ dan taraf signifikansi 0,05 diperoleh $\mathrm{t}_{\text {tabel }}$ sebesar 1,67 . 


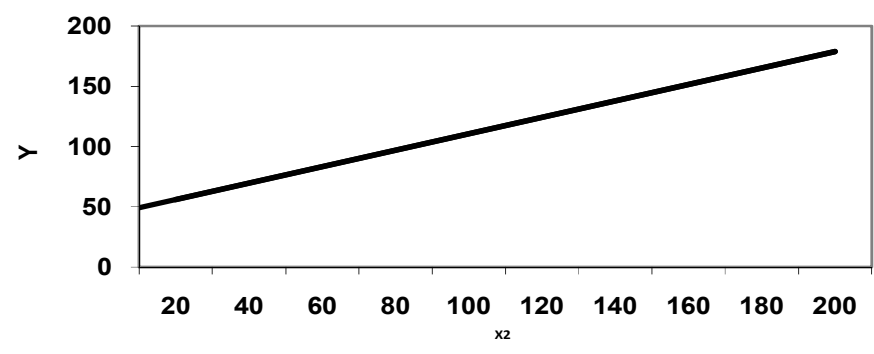

Gambar 4. Model Hubungan antara Kepribadian Dasar

Dosen dengan Kinerja dosen.

Jika dibandingkan dengan thitung, dapat diketahui bahwa nilai $t_{\text {hitung }}>t_{\text {tabel, }}$ sehingga dapat disimpulkan bahwa antara kepribadian dasar dengan kinerja dosen menunjukkan korelasi "signifikansi berarti".

Nilai koefisien determinasi diperoleh dengan mengkuadratkan nilai koefisien korelasi antara $X_{2}$ dengan $Y$, yaitu sebesar $(0,7239)^{2}=0,5240$. Nilai tersebut mengartikan bahwa sekitar $52,40 \%$ variasi yang terjadi pada kinerja dosen dapat dijelaskan oleh variasi kepribadian-dasar dosen melalui persamaan regresi sederhana, yaitu $\mathrm{Y}=46,03+0,680 \mathrm{X}_{2}$.

Hubungan antara Kompetensi Dosen $\left(\mathrm{X}_{3}\right)$ dengan Kinerja Dosen (Y). Pengujian dengan menggunakan teknik analisis regresi dan korelasi sederhana. Analisis regresi sederhana $\mathrm{Y}$ atas $\mathrm{X}_{3}$ menghasilkan persamaan garis linier $=41,70+0,731 \mathrm{X}_{3} \mathrm{Y}$ Pada persamaan regresi tersebut nilai konstanta adalah 41,70 . Nilai koefisien variabel $\mathrm{X}_{3}$ adalah 0,731 artinya bahwa setiap unit kenaikan 1 unit kompetensi dosen akan menaikkan 0,731 unit kinerja dosen di tambah dengan nilai konstanta 41,70.

Hasil dari proses perhitungan linearitas dan uji keberartian regresi, didapatkan beberapa harga yang dapat digunakan sebagai dasar membuat kesimpulan. Hasil analisis ditunjukkan pada tabel Anava sebagai berikut.

Tabel 3. Tabel Anava untuk Uji Signifikansi dan Linearitas Regresi.

$$
\widehat{\mathrm{Y}} \text { linear }=41,70+0,731 \mathrm{X}_{3} \text {. }
$$

\begin{tabular}{ccrrrc}
\hline Sumber Varian & $\mathrm{db}$ & \multicolumn{1}{c}{ JK } & RJK & $\mathrm{F}_{\text {hitung }}$ & $\begin{array}{c}\mathrm{F}_{\text {tabel }} \\
\square=0,05\end{array}$ \\
\hline Total & 78 & 1571154.00 & & & \\
Regresi (a) & 1 & 1554588.80 & 1571154.00 & & \\
Regresi (b/a) & 1 & 9552,03 & 9552,03 & 106,24 & 3,96 \\
Sisa & 78 & 7013,17 & 89,91 & & \\
Tuna Cocok & 40 & 4437,26 & 110,93 & 1,43 & 1,69 \\
Galat & 38 & 2575,92 & 77,79 & & \\
\hline
\end{tabular}


Keterangan: $* *=$ Regresi sangat signifikan $\left(\mathrm{F}_{\mathrm{h}}=106,24>\mathrm{F}_{\mathrm{t}(0,05)}=3,96\right) ;{ }^{\text {ns }}=$ Regresi berbentuk linear $\left(\mathrm{F}_{\mathrm{h}} 1,43<\mathrm{F}_{\mathrm{t}(0,05)}=1,69\right)$; $\mathrm{db}=$ derajat bebas; $\mathrm{JK}=$ Jumlah Kuadrat; $\mathrm{RJK}=$ Rerata Jumlah Kuadrat.

Berdasarkan Tabel 3, hasil perhitungan uji signifikansi regresi menunjukkan harga regresi $F_{\text {hitung }}$ diperoleh nilai sebesar 106,24. Sedangkan harga $F_{\text {tabel }}$ dengan db pembilang $=\mathrm{db}$ regresi yaitu 1 dan penyebut $=\mathrm{db}$ sisa yaitu 78 pada taraf signifikansi 0,05 adalah sebesar 3,96 didapatkan bahwa nilai $\mathrm{F}_{\text {hitung }}>\mathrm{F}$ tabel.

Dari hasil tersebut di atas, dapat disimpulkan bahwa regresi "sangat signifikan" dengan persamaan $\mathrm{Y}=41,70+0,731 \mathrm{X}_{3}$, atau dengan kata lain terdapat hubungan yang signifikan dan berbentuk persamaan regresi linear antara kompetensi dosen dengan kinerja dosen. Persamaan ini dapat diartikan bahwa peningkatan satu unit nilai pada kompetensi dosen menyebabkan peningkatan sebesar 0,731 unit ditambah nilai konstanta 41,70 unit nilai pada kinerja dosen.

Hasil dari perhitungan uji linearitas didapatkan $F_{\text {tuna cocok }}$ sebesar 1,43 sedangkan $\mathrm{F}_{\text {tabel }}=1,69$ pada taraf signifikan 0,05 (dengan pembilang $=\mathrm{db}$ tuna cocok $=40$ dan penyebut $=\mathrm{db}$ galat $=38$ ). Dengan demikian bahwa nilai $\mathrm{F}_{\text {tuna cocok }}<$ dari $\mathrm{F}_{\text {tabel. }}$ Dari hasil tersebut dapat simpulkan bahwa bentuk regresi $\mathrm{Y}$ atas $\mathrm{X}_{3}$ adalah linear.

Bentuk hubungan antara kompetensi dosen dengan kinerja dosen melalui persamaan $\mathrm{Y}=41,70+0,731 \mathrm{X}_{3}$ dapat digambarkan dalam bentuk model hubungan pada gambar sebagai berikut:

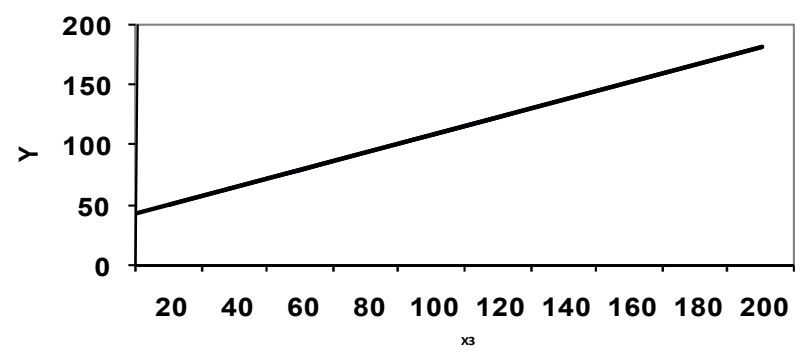

Gambar 5. Model Hubungan antara Kompetensi Dosen dengan Kinerja Dosen.

Nilai koefisien korelasi sederhana ( $\mathrm{r}$.y3) antara kompetensi dosen kampus $\left(\mathrm{X}_{3}\right)$ dengan kinerja dosen (Y) sebesar 0,7594. Dengan hasil nilai tersebut berarti antara kompentensi dosen dengan kinerja dosen saling terdapat keterkaitan sebesar 75,94\%. Hasil hitung pengujian keberartian korelasi dengan menggunakan uji-t menghasilkan thitung $=31,68$. Nilai tabel dengan daftar distribusi $\mathrm{t}$ untuk $\mathrm{db}=78$ dan taraf signifikansi 0,05 diperoleh $t_{\text {tabel }}$ sebesar 1,67. Jika dibandingkan dengan $t_{\text {hitung, dapat diketahui bahwa nilai }}$ $t_{\text {hitung }}>t_{\text {tabel, }}$ sehingga dapat disimpulkan bahwa antara kompetensi dosen dengan kinerja dosen menunjukkan korelasi "signifikansi berarti".

Nilai koefisien determinasi diperoleh dengan mengkuadratkan nilai koefisien korelasi antara $\mathrm{X}_{3}$ dengan $\mathrm{Y}$ yaitu sebesar $(0,7594)^{2}=0,5766$.

Nilai tersebut mengartikan bahwa sekitar 57,66 \% variasi yang terjadi pada kinerja dosen dapat dijelaskan oleh variasi kompetensi dosen melalui persamaan regresi sederhana, yaitu $\mathrm{Y}=41,70+0,731 \mathrm{X}_{3}$. 
Hubungan antara Budaya-Mikro ( $\left.\mathbf{X}_{4}\right)$ dengan Kinerja Dosen (Y). Pengujian dengan menggunakan teknik analisis regresi dan korelasi sederhana. Analisis regresi sederhana $\mathrm{Y}$ atas $\mathrm{X}_{4}$ menghasilkan persamaan garis linier $=33,84+0,7906 \mathrm{X}_{4}$. Pada persamaan regresi tersebut nilai konstanta adalah 33,84. Nilai koefisien variabel $\mathrm{X}_{4}$ adalah 0,79 artinya bahwa setiap unit kenaikan 1 unit budaya-mikro akan menaikkan 0,79 unit kinerja dosen ditambah dengan nilai konstanta 33,84.

Hasil dari proses perhitungan linearitas dan uji keberartian regresi, didapatkan beberapa harga yang dapat digunakan sebagai dasar membuat kesimpulan. Hasil analisis ditunjukkan pada tabel Anava sebagai berikut.

Tabel 4. Tabel Anava untuk Uji Signifikansi dan Linearitas Regresi.

\begin{tabular}{cccccc} 
& $\hat{Y}$ & \multicolumn{2}{c}{ linear $=33,84+0,7906 \mathrm{X}_{4}$} \\
Sumber Varian & $\mathrm{db}$ & $\mathrm{JK}$ & $\mathrm{RJK}$ & $\mathrm{F}_{\text {hitung }}$ & $\mathrm{F}_{\text {tabel }}$ \\
\hline Total & 78 & 1571154.00 & & & \\
\hline Regresi (a) & 1 & 1554588.80 & 1571154.00 & & \\
Regresi (b/a) & 1 & 11327,40 & 1339548,80 & 168,69 & 3,96 \\
Sisa & 78 & 5237,80 & 67,15 & & \\
Tuna Cocok & 42 & 3099,46 & 73,80 & 1,24 & 1,72 \\
Galat & 36 & 2138,33 & 59,40 & & \\
\hline
\end{tabular}

Keterangan: $* *=$ Regresi sangat signifikan $\left(\mathrm{F}_{\mathrm{h}}=168,69>\mathrm{F}_{\mathrm{t}(0,05)}=3,96\right) ;{ }^{\text {ns }}=$ Regresi berbentuk linear $\left(\mathrm{F}_{\mathrm{h}} 1,24<\mathrm{F}_{\mathrm{t}(0,05)}=1,72\right)$; $\mathrm{db}=$ derajat bebas; JK = Jumlah Kuadrat; $\mathrm{RJK}=$ Rerata Jumlah Kuadrat.

Berdasarkan Tabel 4, hasil perhitungan uji signifikansi regresi menunjukkan harga regresi $F_{\text {hitung }}$ diperoleh nilai sebesar 168,69 . Sedangkan harga $F_{\text {tabel }}$ dengan db pembilang $=\mathrm{db}$ regresi yaitu 1 dan penyebut $=\mathrm{db}$ sisa yaitu 78 pada taraf signifikansi 0,05 adalah sebesar 3,96 didapatkan bahwa nilai $\mathrm{F}_{\text {hitung }}>\mathrm{F}$ tabel.

Dari hasil tersebut di atas, dapat disimpulkan bahwa regresi "sangat signifikan" dengan persamaan $\mathrm{Y}=33,84+0,7906 \mathrm{X}_{4}$, atau dengan kata lain terdapat hubungan yang signifikans dan berbentuk persamaan regresi linear antara budaya-mikro dengan kinerja dosen. Persamaan ini dapat diartikan bahwa peningkatan satu unit nilai pada budaya-mikro menyebabkan peningkatan sebesar 0,7906 unit ditambah nilai konstanta 31,75 unit nilai pada kinerja dosen.

Hasil dari perhitungan uji linearitas didapatkan $F_{\text {tuna cocok }}$ sebesar 1,24 sedangkan $\mathrm{F}_{\text {tabel }}=1,72$ pada taraf signifikan 0,05 (dengan pembilang $=\mathrm{db}$ tuna cocok $=42$, dan penyebut $=\mathrm{db}$ galat $=36$ ). Dengan demikian bahwa nilai $\mathrm{F}_{\text {tuna cocok }}<$ dari $\mathrm{F}_{\text {tabel. }}$ Dari hasil tersebut dapat simpulkan bahwa bentuk regresi $\mathrm{Y}$ atas $\mathrm{X}_{1}$ adalah linear.

Bentuk hubungan antara budaya-mukro dengan kinerja dosen melalui persamaan $\mathrm{Y}=33,84+0,7906 \mathrm{X}_{4}$ dapat digambarkan dalam bentuk model hubungan pada gambar sebagai berikut: 


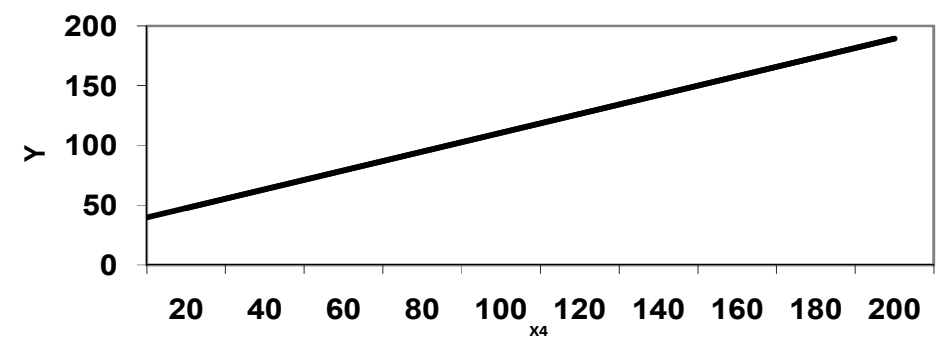

Gambar 6. Model Hubungan antara Budaya-mikro dengan Kinerja Dosen

Nilai koefisien korelasi sederhana ( $\left.\mathrm{r}_{\mathrm{y}} 4\right)$ antara budaya-mikro $\left(\mathrm{X}_{4}\right)$ dengan kinerja dosen (Y) sebesar 0,8269. Dengan hasil nilai tersebut berarti antara budaya-mikro dengan kinerja dosen saling terdapat keterkaitan sebesar 82,69\%. Hasil hitung pengujian keberartian korelasi dengan menggunakan uji-t menghasilkan $t_{\text {hitung }}=46,19$. Nilai $t_{\text {tabel }}$ dengan daftar distribusi $t$ untuk $\mathrm{db}=78$ dan taraf signifikansi 0,05 diperoleh $\mathrm{t}_{\text {tabel }}$ sebesar 1,67. Jika dibandingkan dengan $t_{\text {hitung, dapat diketahui bahwa nilai thitung }}>t_{\text {tabel, }}$ sehingga dapat disimpulkan bahwa antara budaya-mikro dengan kinerja dosen menunjukkan korelasi "signifikansi berarti". Nilai koefisien determinasi diperoleh dengan mengkuadratkan nilai koefisien korelasi antara $\mathrm{X}_{4}$ dengan $\mathrm{Y}$, yaitu sebesar $(0,8269)^{2}=$ 0,6338. Nilai tersebut mengartikan bahwa sekitar $63,38 \%$ variasi yang terjadi pada kinerja dosen dapat dijelaskan oleh variasi budaya-mikro melalui persamaan regresi sederhana, yaitu $\mathrm{Y}=33,84+0,7906 \mathrm{X}_{4}$.

Hubungan antara Social capital (Xs) dengan Kinerja Dosen (Y). Pengujian dengan menggunakan teknik analisis regresi dan korelasi sederhana. Analisis regresi sederhana $Y$ atas $\mathrm{X}_{5}$ menghasilkan persamaan garis linier $=29,39+0,8039 \mathrm{X}_{5}$. Pada persamaan regresi tersebut nilai konstanta adalah 29,39. Nilai koefisien variabel $\mathrm{X}_{5}$ adalah 0,8039 artinya bahwa setiap unit kenaikan 1 unit social capital akan menaikkan 0,8039 unit kinerja dosen ditambah dengan nilai konstanta 29,39. Hasil dari proses perhitungan linearitas dan uji keberartian regresi, didapatkan beberapa harga yang dapat digunakan sebagai dasar membuat kesimpulan. Hasil analisis ditunjukkan pada tabel Anava sebagai berikut.

Tabel 5. Tabel Anava untuk Uji Signifikansi dan Linearitas Regresi

\begin{tabular}{|c|c|c|c|c|c|}
\hline \multirow{2}{*}{ Sumber Varian } & \multirow{2}{*}{$\mathrm{Db}$} & \multirow{2}{*}{ JK } & \multirow{2}{*}{ RJK } & \multirow{2}{*}{$F_{\text {hitung }}$} & $\mathrm{F}_{\text {tabel }}$ \\
\hline & & & & & $\square=0,05$ \\
\hline Total & 78 & 1571154.00 & & & \\
\hline Regresi (a) & 1 & 1554588.80 & 1554588.80 & & \\
\hline Regresi (b/a) & 1 & 10417,28 & 10417,28 & 132,17 & 3,96 \\
\hline Sisa & 78 & 6147,92 & 78,82 & & \\
\hline Tuna Cocok & 35 & 2892,74 & 76,12 & 0,94 & 1,69 \\
\hline Galat & 43 & 3255,18 & 81,38 & & \\
\hline
\end{tabular}


Keterangan: $* *=$ Regresi sangat signifikan $\left(\mathrm{F}_{\mathrm{h}}=132,17>\mathrm{F}_{\mathrm{t}(0,05)}=3,96\right) ;{ }^{\mathrm{ns}}=$ Regresi berbentuk linear $\left(\mathrm{F}_{\mathrm{h}} 1,079<\mathrm{F}_{\mathrm{t}(0,05)}=1,68\right)$; $\mathrm{db}=$ derajat bebas; JK = Jumlah Kuadrat; $\mathrm{RJK}=$ Rerata Jumlah Kuadrat.

Berdasarkan tabel di atas, hasil perhitungan uji signifikansi regresi menunjukkan harga regresi $F_{\text {hitung }}$ diperoleh nilai sebesar 39,70. Sedangkan harga $F_{\text {tabel }}$ dengan $d b$ pembilang $=\mathrm{db}$ regresi yaitu 1 dan penyebut $=\mathrm{db}$ sisa yaitu 78 pada taraf signifikansi 0,05 adalah sebesar 3,96 didapatkan bahwa nilai $\mathrm{F}_{\text {hitung }}>\mathrm{F}$ tabel.

Dari hasil tersebut di atas, dapat disimpulkan bahwa regresi " sangat signifikan" dengan persamaan $\mathrm{Y}=29,39+0,8039 \mathrm{X}_{5}$, atau dengan kata lain terdapat hubungan yang signifikans dan berbentuk persamaan regresi linear antara social capital dengan kinerja dosen. Persamaan ini dapat diartikan bahwa peningkatan satu unit nilai pada social capital menyebabkan peningkatan sebesar 0,8039 unit ditambah nilai konstanta 29,39 unit nilai pada kinerja dosen.

Hasil dari perhitungan uji linearitas didapatkan $F_{\text {tuna cocok }}$ sebesar 0,94 sedangkan $\mathrm{F}_{\text {tabel }}=1,69$ pada taraf signifikan 0,05 (dengan pembilang $=\mathrm{db}$ tuna cocok $=38$, dan penyebut $=\mathrm{db}$ galat $=40)$. Dengan demikian bahwa nilai $\mathrm{F}_{\text {tuna cocok }}<$ dari $\mathrm{F}_{\text {tabel. }}$ Dari hasil tersebut dapat disimpulkan bahwa bentuk regresi $\mathrm{Y}$ atas $\mathrm{X}_{1}$ adalah linear.

Bentuk hubungan antara social capital dengan kinerja dosen melalui persamaan $Y$ $=29,39+0,8039 \mathrm{X}_{5}$ dapat digambarkan dalam bentuk model hubungan pada gambar sebagai berikut:

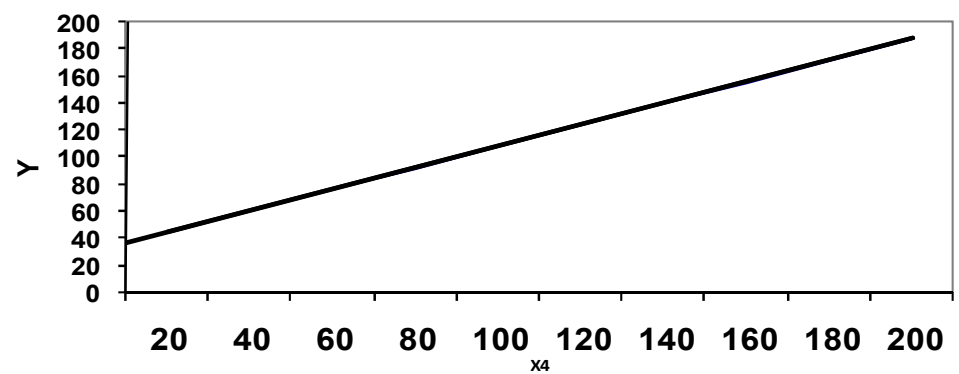

\section{Gambar 7. Model Hubungan antara Social capital dengan Kinerja Dosen.}

Nilai koefisien korelasi sederhana ( $\left.\mathrm{r}_{\mathrm{y}} 5\right)$ antara social capital $\left(\mathrm{X}_{5}\right)$ dengan kinerja dosen (Y) sebesar 0,7930. Dengan hasil nilai tersebut berarti antara social capital dengan kinerja dosen saling terdapat keterkaitan sebesar 79,30\%. Hasil hitung pengujian keberartian korelasi dengan menggunakan uji-t menghasilkan thitung $=37,74$. Nilai tabel dengan daftar distribusi $t$ untuk $\mathrm{db}=78$ dan taraf signifikansi 0,05 diperoleh $\mathrm{t}_{\text {tabel }}$ sebesar

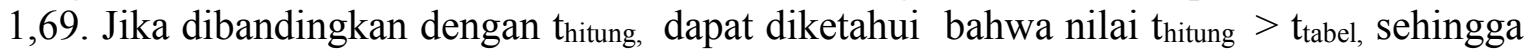
dapat disimpulkan bahwa antara social capital dengan kinerja dosen menunjukkan korelasi "signifikansi berarti".

Nilai koefisien determinasi diperoleh dengan mengkuadratkan nilai koefisien korelasi antara $\mathrm{X}_{5}$ dengan $\mathrm{Y}$ yaitu sebesar $(0,7930)^{2}=0,6289$. Nilai tersebut mengartikan bahwa sekitar $62,89 \%$ variasi yang terjadi pada kinerja dosen dapat dijelaskan oleh variasi social capital melalui persamaan regresi sederhana, yaitu $\mathrm{Y}=$ $27,43+0,8039 \mathrm{X}_{5}$. 


\section{PENUTUP}

Terdapat hubungan positif dan searah antara komitmen organisasi dengan kinerja dosen. Keduanya saling ada keterkaitan dan berjalan searah, yang artinya, setiap unit peningkatan komitmen organisasi, akan meningkatkan kinerja dosen. Semakin tinggi peningkatan komitmen organisasi, semakin baik pula kinerja dosen.

Terdapat hubungan positif dan searah antara kepribadian-dasar dosen dengan kinerja dosen. Keduanya saling ada keterkaitan dan berjalan searah, yang artinya, setiap unit peningkatan kepribadian-dasar, akan meningkatkan kinerja dosen. Semakin tinggi peningkatan kepribadian-dasar, semakin baik pula kinerja dosen.

Terdapat hubungan positif dan searah antara kompetensi dosen dengan kinerja dosen. Keduanya saling ada keterkaitan dan berjalan searah, yang artinya, setiap unit peningkatan kompetensi dosen, akan meningkatkan kinerja dosen. Semakin tinggi peningkatan kompentensi dosen, semakin baik pula kinerja dosen.

Terdapat hubungan positif dan searah antara komitmen organisasi, didukung dengan budaya-mikro dan social capital dengan kinerja dosen. Hubungan tersebut saling ada keterkaitan dan berjalan searah, yang artinya, setiap unit peningkatan komitmen organisasi didukung dengan peningkatan budaya-mikro dan peningkatan social capital, akan meningkatkan kinerja dosen. Semakin tinggi peningkatan komitmen organisasi didukung peningkatan budaya-mikro dan social capital maka semakin baik pula kinerja dosen.

Terdapat hubungan positif dan searah antara kepribadian-dasar didukung dengan budaya-mikro dan social capital dengan kinerja dosen. Hubungan tersebut saling ada keterkaitan dan berjalan searah, yang artinya, setiap unit peningkatan kepribadian-dasar didukung dengan peningkatan budaya-mikro dan peningkatan social capital, akan meningkatkan kinerja dosen. Semakin tinggi peningkatan kepribadian-dasar didukung peningkatan budaya-mikro dan social capital maka semakin baik pula kinerja dosen.

Terdapat hubungan positif dan searah antara kompetensi dosen didukung dengan budaya-mikro dan social capital dengan kinerja dosen. Hubungan tersebut saling ada keterkaitan dan berjalan searah, yang artinya, setiap unit peningkatan kompetensi dosen didukung dengan peningkatan budaya-mikro dan peningkatan social capital, akan meningkatkan kinerja dosen. Semakin tinggi peningkatan kompetensi dosen didukung peningkatan budaya-mikro dan social capital, akan semakin baik pula kinerja dosen.

Terdapat hubungan positif dan searah antara komitmen organisasi, kepribadiandasar dan kompetensi dosen didukung dengan budaya-mikro dan social capital dengan kinerja dosen. Hubungan tersebut saling ada keterkaitan dan berjalan searah, yang artinya, setiap unit peningkatan komitmen organisasi, kepribadian-dasar dan kompetensi dosen didukung dengan peningkatan budaya-mikro dan peningkatan social capital, akan meningkatkan kinerja dosen. Semakin tinggi peningkatan komitmen organisasi, kepribadian-dasar dan kompetensi dosen yang didukung peningkatan budaya-mikro dan social capital, akan semakin baik pula kinerja dosen.

\section{DAFTAR RUJUKAN}

Aniket Nagle, Peter Wolf, Robert Riener. (2015) "Towards a system of customized video game mechanics based on player personality: Relating the Big Five personality traits 
with difficulty adaptation in a first-person shooter game" . Entertainment Computing Journal, Volume 13, March 2015, Pages 10-24

Chet Robie, Stephen D. Risavy. (2015) "A comparison of frame-of-reference and frequency-based personality measurement". Personality and Individual Differences Journal, Volume 92, April 2015, Pages 16-21

Cohen, S., Prusak L. (2001) In Good Company: How Social Capital Makes Organization Work. London: Harvard Business Pres.

Daft, Richard L., (2003) Management. Sixth Edition. Ohio: Thomson South-Western.

Dessler, Gary, (2005) Human Resources Management. Tenth Edition, International Edition. New Jersey: Prentice-Hall / Pearson Education, Inc.

Emine Yılmaz, Gökhan, Özer \& Mehmet Günlük. (2014) "Do Organizational Politics and Organizational Commitment Affect Budgetary Slack Creation in Public Organizations?". Procedia - Journal Social and Behavioral Sciences, Volume 150, 15 September 2014, Pages 241-250, 10th International Strategic Management Conference 2014.

Erkut Altındağ,, Yeliz Kösedağı. (2015) "The Relationship Between Emotional Intelligence of Managers, Innovative Corporate Culture and Employee Performance" Procedia - Social and Behavioral Sciences Jounal: Volume 210, 2 December 2015, Pages 270-282 Proceedings of the 4th International Conference on Leadership, Technology, Innovation and Business Management (ICLTIBM-2014)

George, Jennifer M., and Gareth R. Jones. (2002) Organizational Behavior. Third Edition. New Jersey: Pearson Education, Inc.

Giedrè Genevičiūtè-Janonienè \& Auksè Endriulaitienè. (2014) “Employees' Organizational Commitment: Its Negative Aspects For Organizations". Procedia Journal Social and Behavioral Sciences Volume 140, 22 August 2014, Pages 558564. 2nd World Conference on Psychology and Sociology, PSYSOC 2013, 27-29 November 2013, Brussels, Belgium.

Greenbberg, Gardner, W. Jhon. (2015) On Leadership. New York: The Free Press. A Division of Mac Millan, Inc.

Griffin, Ricky W., and Ronald J. Ebert. (2006) Business. Eighth Edition, International Edition. New Jersey: Prentice-Hall / Pearson.

Jousairi, (2014) Sosial Capital (Menuju Keunggulan Budaya Manusia Indonesia). Jakarta: MR United Press

Kinicki, Angelo, and Robert Kreitner. (2003) Organizational Behavior. Key Concepts, Skills \& Best Practices. International Edition. New York: McGraw-Hill \& Irwin.

Lukman Imam Syafii', Armanu Thoyib, Umar Nimran, Djumahir. (2015) "The Role of Corporate Culture and Employee Motivation as a Mediating Variable of Leadership Style Related with the Employee Performance (Studies in Perum Perhutani)". Procedia - Social and Behavioral Sciences Journal. Volume 211, 25 November 2015, Pages 1142-1147. 2nd Global Conference on Business and Social Sciences (GCBSS-2015) on "Multidisciplinary Perspectives on Management and Society", 17- 18 September, 2015, Bali, Indonesia

M.P. Pattussi' M.T. Anselmo Olinto' H.B. Rower, F. Souza de Bairros' (2015) 'Individual and neighbourhood social capital and all-cause mortality in Brazilian adults: a prospective multilevel study" Public Health Journal. Available online 22 January 2015 In Press, Corrected Proof — Note to users 
Martin Gartmeier, Markus Gebhardt Benjamin Dotger. (2015) "How do teachers evaluate their parent communication competence? Latent profiles and relationships to workplace behaviors". Teaching and Teacher Education Journal. Volume 55, April 2015, Pages 207-216

Meghann L. Drury-Grogan. (2014) "Performance on agile teams: Relating iteration objectives and critical decisions to project management success factors" Information and Software Technology Journal. Volume 56, Issue 5, May 2014, Pages 506-515

Mello, Jeffrey A. (2002) Strategic Human Resource Management. Cincinnati, Ohio: South-Western College Publishing.

Milkovich, George T., and Jerry M. Newman. (2005) Compensation. Eighth Edition. NewYork: McGraw-Hill \& Irwin.

Ressi Dwiana. (2014) "Korean wave, imperialisme budaya, dan komersialisasi Media" Jurnal Komunikasi, Universi tas Tarumanagara, Tahun VI/01/2014

Robbins, P. Stephen dan JudgeTimothy A. (2008) Organizational Behavior, $12^{\text {th }} \mathrm{ed}$, buku 1, terjemahan Diana Angelica. Jakarta: Salemba empat.

Robbins, Stephen P. (2005) Organizational Behavior. Eleventh Edition. International Edition. New Jersey. Prentice-Hall / Pearson.

Sagala, Syaiful. (2013) Manajemen Berbasis Sekolah dan Masyarakat. Jakarta: PT. Nimas Multima.

Schermerhorn, John R., Jr., (2005) Management. Eighth Edition. New York: John Wiley $\&$ Sons, Inc.

Soehardi, Sigit. (2013) Perilaku Organisasional. Yogyakarta: Lukman offset

Sugiyono. (2013) Metode Penelitian Manajemen: Pendekatan, Kuantitatif, Kualitatif, Kombinasi (Mixed Methods), Penelitian Tindakan (Action Research), Penelitian Evaluasi. Bandung: Alfabeta.

W. J. Probert, K. Shea, C. J. Fonnesbeck, M. C. Runge, T. E. Carpenter, S. Dürr, M. G. Garner, N. Harvey, M. A. Stevenson, C. T. Webb, M. Werkman, M. J. Tildesley, M. J. Ferrari. (2015) "Decision-making for foot-and-mouth disease control: Objectives matter". Epidemics Journal Volume 15, June 2015, Pages 10-19 